\title{
Cerebrovascular lesions in parkinsonian patients: when do they really matter?
} Lesões cerebrovasculares no parkinsoniano: quando elas realmente importam? Henrique Ballalai Ferraz, James Yared

Department of Neurology, Universidade Federal de São Paulo, Escola Paulista de Medicina, São Paulo SP, Brazil.

\section{Correspondence} Henrique Ballalai Ferraz Alameda Casa Branca 805 / apto 141 01408-001 São Paulo SP - Brasil. E-mail:henrique_ferraz@uol.com.br Conflict of interest There is no conflict of interest to declare.

Received 11 August 2013 Accepted 19 August 2013

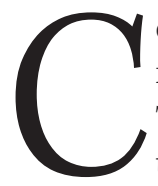
erebrovascular disorder is a relatively uncommon cause of parkinsonism but its recognition is important since it may be confounded with many other etiologies. The classical clinical features of vascular parkinsonism (VP) includes dementia, urinary incontinence, impairment of stance, freezing of gait, rigidity and bradicinesia mainly of lower limbs ${ }^{1}$. Clinicians have significant difficulties when facing patients with parkinsonism with early onset of axial symptoms and problems with balance and gait since multiple systems atrophy, progressive supranuclear palsy, normal pressure hydrocephalus or VP are plausible diagnoses for this condition.

Zijlmans et al. studied the brains of 17 patients who died with a parkinsonian syndrome without evidence of Lewy body pathology at the mesencephalon and with cerebrovascular abnormalities such as small vessel disease and macroscopic infarcts ${ }^{2}$. They confirmed the tendency of VP to affect the lower limbs and to have a more severe course as compared to Parkinson's disease (PD). They also describe four patients who had a somewhat different clinical course resulting from "strategic" lesions of the contralateral thalamocortical pathway. These patients had asymmetric symptomatology and an acute or delayed progressive onset. Glass et al from the same group later described the clinical correlates of 28 patients (including those first 17 patients) and found that falls, lower body predominance, pyramidal signs are highly prevalent on VP while visual hallucinations are virtually absent in all these patients ${ }^{3}$. The presence of visual hallucinations would be decisive to diagnose PD or dementia with Lewy bodies instead of VP as the cause of the symptoms even in symmetric and axial predominant parkinsonian syndrome.

On this issue of the Arquivos de Neuro-Psiquiatria Vale et al. ${ }^{4}$ present the clinical correlates of 17 Brazilian patients fulfilling the criteria for VP of Zijlmans et al. ${ }^{2}$. They found roughly the same characteristics of other series with lower limbs motor predominance, falls and freezing of gait, urinary incontinence and dementia. A poor response to levodopa was also frequently seen in the patients. Although the clinical characteristics are important to define VP we need laboratorial or radiological data to support the clinical diagnoses. It is not uncommon that typical or atypical parkinsonian patients present cerebrovascular abnormalities on imaging studies of the brain. Are these cerebrovascular abnormalities really meaningful for a given patient?

Magnetic resonance imaging (MRI) of the brain is the technique of choice to diagnose VP due to its greater sensitivity to detect small lesions, mainly in subcortical white matter and deep gray nuclei. FLAIR and conventional T2-(T) SE weighted images are preferred. The main abnormalities are multiple territory infarcts (96\% in VP versus $22 \%$ in PD), periventricular and subcortical white matter lesions (75-90\% in VP versus $7-16 \%$ in PD), and basal ganglia ischaemic lesions (38-44\% in VP versus 4.6-8.0\% in PD) $)^{5}$. White matter lesions are also frequently found in watershed areas and patients with acute onset of symptoms also tend to have gray nuclei lesions (putamen or thalamus alone or in one of these nuclei along with globus pallidus or caudate nucleus). $\mathrm{T} 2^{*}$ and recent susceptibility weighted image techniques are best for detecting hemorrhagic foci ${ }^{1}$.

Diffusion tensor techniques diffusion measures ( fractional anisotropy and mean diffusivity) can show disruption of the microstructural organization of frontal lobe which is associated 
with the severity of $\mathrm{VP}^{6}$. Unfortunately automated methods are yet time consuming and further work is needed to optimize its use in the clinical setting.

Functional imaging can be used to differentiate VP from PD patients, mainly by analyzing presynaptic striatal dopamine transporter. Studies have showed significant reduction in striatal uptake ratios in $\mathrm{PD}$ but not in $\mathrm{VP}^{7,8}$. Nevertheless, some cases may show significantly reduced striatal binding in VP patients, particularly in "strategic" lesions of nigroestriatal pathway. Even if reduced DAT uptake in striatum is seen in VP patients asymmetry index of DAT uptake is usually seen in $\mathrm{PD}$ but not in $\mathrm{VP}^{9}$. Imaging of striatal dopamine transporter helps patient management and finding of normal uptake is associated with no benefit from medications in over $90 \%$ of subjects ${ }^{10}$.

Transcranial sonography (TCS) would be a helpful method to differentiate PD from VP since only in the former there is hyperechogenicity of mesencephalon ${ }^{11}$. On the other hand, a normal TCS is expected in both VP and atypical parkinsonism.

The study of Vega et al. ${ }^{4}$ is welcomed since we need to understand how VP manifests and how should we manage these patients. Considering the importance of this issue and the need to identify true VP patients we need more studies addressing the point of how and where in the CNS the cerebrovascular abnormalities seen on MRI can induce parkinsonian features.

\section{References}

1. Winikates J, Jankovic J. Clinical correlates of vascular parkinsonism. Arch Neurol 1999;56:98-102.

2. Zijlmans JC, Daniel SE, Hughes AJ, Revesz T, Lees AJ. Clinicopathological investigation of vascular parkinsonism, including clinical criteria for diagnosis. Mov Disord 2004;19:630-640.

3. Glass PG, Lees AJ, Bacellar A, Zijlmans J, Katzenschlager R, SilveiraMoriyama L. The clinical features of pathologically confirmed vascular parkinsonism.J Neurol Neurosurg Psychiatry 2012;83:1027-1029.

4. Vale TC, Caramelli P, Cardoso F. Vascular parkinsonsim: a case series of 17 patients. Arq Neuropsiquiatr 2013;71:757-762.

5. Kalra S, Grosset DG, Benamer HT. Differentiating vascular Parkinsonism from idiopathic Parkinson's disease: a systematic review. Mov Disord 2010;25:149-156.

6. Wang HC, Hsu JL, Leemans A. Diffusion tensor imaging of vascular parkinsonism: structural changes in cerebral white matter and the association with clinical severity. Arch Neurol 2012;69:1340-1348.
7. Tzen KY, Lu CS, Yen TC, Wey SP, Ting G. Differential diagnosis of Parkinson's disease and vascular parkinsonism by $(99 \mathrm{~m})$ Tc-TRODAT-1. J Nucl Med 2001;42:408-413.

8. Gerschlager W, Bencsits G, Pirker W, et al. [1231]Beta-CIT SPECT distinguishes vascular parkinsonism from Parkinson's disease. Mov Disord 2002;17:518-523.

9. Benítez-Rivero S, Marín-Oyaga VA, García-Solís D, et al. Clinical features ans 123 I-FP-CIT SPECT imaging in vascular parkinsonism and Parkinson's disease.J Neurol Neurosurg Psychiatry 2013;84:122-129.

10. Antonini A, Vitale C, Barone P, et al. The relationship between cerebral vascular disease and parkinsonism: the VADO study. Parkinsonism Relat Disord 2012;18:775-780.

11. Tsai CF, Wu RM, Huang YW, Chen LL, Yip PK, Jeng JS. Transcranial color-coded sonography helps differentiation between idiopathic Parkinson's disease and vascular parkinsonism. J Neurol 2007;254:501-507. 